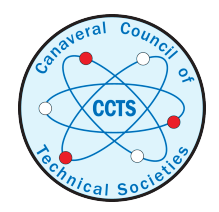

Mar 7th, 8:00 AM

\title{
The Compatibility of Value Engineering and Configuration Management
}

Marvin Wasserman

Brown Engineering Company, Inc.

Follow this and additional works at: https://commons.erau.edu/space-congress-proceedings

\section{Scholarly Commons Citation}

Wasserman, Marvin, "The Compatibility of Value Engineering and Configuration Management" (1966). The Space Congress ${ }^{\circledR}$ Proceedings. 1.

https://commons.erau.edu/space-congress-proceedings/proceedings-1966-3rd/session-8/1

This Event is brought to you for free and open access by the Conferences at Scholarly Commons. It has been accepted for inclusion in The Space Congress ${ }^{\circledR}$

Proceedings by an authorized administrator of Scholarly Commons. For more information, please contact commons@erau.edu.

EMBRYRIDDLE Aeronautical University SCHOLARLY COMMONS 
Marvin Wasserman

Brown Engineering Company, Inc. Huntsville, Alabama

\section{Summary}

This report is aimed at management levels responsible for ensuring system compatibility and mission success. The report provides a familiarization with the philosophies of system management and the interrelationships of program management, system engineering, and management tools. Value Engineering and Configuration Management are discussed as the catalysts to be integrated into the management network, thus assuring system compatibility and mission success at the lowest overall cost.

The Aerospace Industries Association (AIA) has openly stated that Configuration Management and Value Engineering are not compatible. This paper is offered in rebuttal to that statement.

\section{About the Author}

Mr. Wasserman is a graduate of Glendale College, California. He was associated with the Bendix Corporation for 9 years and Ling-TemcoVaught, Michigan Division for a short period prior to joining Brown Engineering Company, Inc.

In the field of Configuration Management, his knowledge of current System Management concepts provides an excellent background for discharging the duties of Configuration Management Consultant.

Currently, he is serving as a Configuration Management Consultant to the System Engineering Department and corporate staff of Brown Engineering Company, Inc., Huntsville, Alabama. $\mathrm{He}$ is a representative for the Value Engineering and Cost Reduction Program conducted on a corporate-wide basis at Brown Engineering Company, In the latter capacity, Mr. Wasserman works closely with management in continuously striving towards the efficient identification and elimination of unnecessary costs on all projects undertaken by the System Engineering Department.

Mr. Wasserman is secretary of the Redstone Alabama Chapter of "SAVE" and Editor and Publisher of the Chapter's Value Engineering Newsletter. He was recently honored by the Chapter for his outstanding Newsletter which has gained national recognition.

\section{Background}

Let us first visualize what has happened in the aerospace and weapon system technology and procurement over the past decade.
Decision making techniques were developed during the time period when concurrency or telescoping was first introduced in 1955, and during the advent of the ballistic missile systems in 1959. The techniques dealt with the management of changes, status reporting, and system compatibility. When properly applied, these techniques proved effective and timely.

Needed improvements were obvious to those facing development of systems which had become more complex, detailed, and costly than ever before. Concurrently, more emphasis was being placed on logistics, data handling, contract performance, and program definition.

Indeed here was a challenge to American ingenuity. The challenge was met by both industry and government. Special committees and ad hoc committees were established to revise or build other timely and effective decisionmaking techniques and methodology to insure system compatibility. Among these committees were those established to study Value Engineering and Configuration Management implementation.

Definition of this condition is beginning through a so called "coordinated effort". A more uniform approach towards procurement is definitely underway. New and revised management techniques compatible with system management philosophy have come into focus, (i.e., Configuration Management, Value Engineering, cost effectiveness, and PERT/Cost). New functional technologies such as system effectiveness, product assurance, and product support have been grouped into effective management tools which are aiding tremendously in reaching the objectives of the uniform approach.

The Department of Defense (DOD) under the direction of Secretary Robert S. McNamara has accomplished much and in many instances has been the driving force in resolving these problems. Quote from ORDNANCE Nov-Dec 1965, "It is very difficult to argue effectively against most of basic McNamara management innovations, They are indeed geared to more effective decision-making and more efficient procurement."

A multitude of DOD Directives accomplished much to alleviate the problems. Among these are DOD Dir \#3200.9 "Contract Definition", DOD Dir \#3200.6 "Reporting of Research, Development, and Engineering Program Information", DOD Dir \#7045. 2 "Procedures for Program Control and Related Progress Reporting", and the DOD Dir \# (Draft) establishing DOD policies and criteria 
governing the Configuration Management of systems and equipment including related facilities and military construction.

The National Aeronautics and Space Administration (NASA) has recently released a directive prescribing policy and guidelines for planning, approval, and conduct of major research and development projects. This directive and the subsequent amplification represent a major milestone in NASA's efforts to accomplish a more uniform approach towards procurement. NASA Policy Directive $7121-1$ will be discussed later in this paper.

\section{Relationships}

There is a known relationship between program management, Configuration Management, and Value Engineering. Figure 1 expresses this known relationship as well as the inter-relationships of program management, system engineering, and the other functional disciplines or tools of management. The program manager coupled with his highly qualified technical and managerial staff composes program management. This organization provides the driving force to plan, organize, coordinate, control, and direct all effort to accomplish system objectives. System engineering is responsible to program management for ascertaining and maintaining technical integrity over all elements of a system. The functional disciplines or tools of management mesh with program management and system engineering to provide the coordinating links. Meshing with system engineering is the system or program, and standardization. Once the program achieves momentum from the driving force provided by program management, the program will move from conceptual through definition, acquisition, and operational phases. The controls are maintained by DOD or other cognizant Government agencies. A system in development can be cancelled or reverted back to definition at any time.

The standardization gear shown in Figure 1 , has intentionally been assembled to mesh with system engineering, and for a multitude of reasons. First, procurement cannot effectively ensure maximum uniformity of items of supply without the full support and cooperation of system engineering. The other functional disciplines of management, in retrospect, cannot act with full awareness of the inter-relationships of their responsibilities, functions, and actions without some type of standardized uniform methodology. Therefore, standardization provides a needed catalyst for today's complex procurement processes. Not only will it ensure maximum uniformity of items of supply, but effective engineering management, and procurement understanding as well.

\section{What is Configuration Management?}

The inter-relationships of the various organizational elements which contribute to the system definition, change, and status accounting are involved intimately with Configuration Management. It is not a new technique of management, but a more sophisticated approach to the management of systems. Therefore, Configuration Management is primarily a management discipline involving the inter-relationships of the various organizational elements which contribute to the product definition, change, and status.

The program manager, who is responsible for making all decisions, depends upon Configuration Management to provide the formal procedural concepts. This is erroneously identified by many as "change management". But, when change management is elevated to include the management of the technical description or definition and status accounting, it must be termed Configuration Management.

Configuration Management defined functionally is a discipline applying technical and administrative direction and surveillance to (1) properly identify; (2) control changes to; and (3) record the change implementation status of the total configuration of systems or equipment.

Defined formally, Configuration Management is the management of technical requirements which define systems (system equipment or individual equipment) and changes thereto. Implementation is provided through a formal set of procedural concepts by which uniform and mutually supporting methods for configuration identification, control, and accounting are established and maintained for systems and system components.

The objectives of Configuration Management as stated by the DOD Directive are:

A. To provide, during the three defined life cycle periods, the level of configuration identification, control, and status accounting necessary to as sist manage ment in achieving improved hardware per formance, operational efficiency, logistic support and weapon readiness.

B. To attain maximum management efficiency in the timing, content, evaluation, implementation, and recording of configuration changes.

C. To attain optimum uniformity in configuration management, forms, and reports at all interfaces of the DOD and industry. 
In retrospect, isn't VaIue Engineering a management discipline? It also is involved with the inter-relationships of the various organizational elements which contribute to product definition, change, and status. But its objective is to produce the system at the lowest overall cost without jeopardizing reliability, quality, or the product's system effectiveness.

The draft of U. S. Army Missile Command's Value Engineering Program objective states that:

"The objective of the Missile Command's Value Engineering Program is to field functionally simplified mission items at the lowest practicable overall cost, with respect to time, material, equipment, facilities and personnel without degradation in required quality, reliability, perform ance, maintainability, interchangeability or delivery schedules."

In summary; the objective is to put into the hands of the user a reliable, operable, economically supportable, and timely available product.

\section{Total Change Impacting}

For some time costs being expended on changes to system/equipments have been staggering. Were these changes absolutely required to meet system objectives? Was the full impact of the changes considered prior to their implementation? What we needed then were disciplines of Configuration Management.

Today's disciplines of Configuration Management would have insured that all changes were thoroughly evaluated and coordinated prior to implementation. Value Engineering would have insured that changes were evaluated from the value standpoint, i.e., providing the functional change or modification at the lowest overall cost without jeopardizing the operational effectiveness of the system.

By applying Value Engineering techniques to the preparation and formulation of formal procedures required by Configuration Management, the function of each segment of the system can be effected at the lowest overall cost. For example, an engineering release system may require an abundance of forms, cards, and status reports. An examination of forms picked at random may prompt these questions. What does it do? What function does it perform in the overall system? Is it necessary? Will something already existing satisfy its ffunctional requirement at less cost? Is its function satisfying the customer's requirement? These and more questions might be asked of an engineering change procedure, production process, or change control verification system.
Value Engineering, if applied to any or all of these procedures operating today, would enhance their effectiveness and objective without jeopardizing the performance design effort and do it at far less cost. The colloquialism, "If it works, leave it alone. " is unnecessarily stated by many who immediately identify a change with high cost. They visualize costs resulting from requalification testing, revalidation of technical data, tooling changes, and mod-kit costs. They may very well be correct in their belief. Maybe we should continue in this manner and not propose changes.

Following is an excerpt from an AIA (TCRC) Letter.

\section{Conflict with Value Engineering Concept}

"The Value Engineering clauses of ASPR, Part 17, Sections 1-1710 through 1-1708, encourage or require contractors to develop design change proposals for the sake of reducing costs. The goal is legiti mate, commendable, and supported by the Aerospace industry. To do so, however, contractors must analyze requirements, systems, designs, processes, materials, and procedures throughout the development, acquisition, and production phases and, when a means of reducing costs is discovered, they are encouraged to submit a Value Engineering Change Proposal. The keynote of the Value Engineering adherents is that if there is a way to achieve equal results at lower cost, a change should be made in the interest of economy.

The philosophy of Configuration Management, on the other hand, says "If it works, leave it alone." "Don't produce-improve an item just to get $5 \%$ more accuracy or to save $\$ 10,000$. That brilliant cost saving plan may cost us $\$ 10,000,000$ in spare parts replacements, down time, and increased maintenance time." The keynote of the Configuration Management adherents is that it is more important to have a fully identified, working, and ready system than it is to seek methods of cutting costs after a baseline has been established.

Obviously, the two philosophies are incompatible, yet contractors continually find both requirements embodied in their contracts, at the same time, for the same systems. Contractors can support both philosophies, but not on the same program. If Configuration Management is accented by a SPO, then that philosophy will prevail, to the detriment of value engineering. 
This is only one more basic conflict that should be resolved by DOD so that contractors can point their efforts in one direction and not need to waste time and money trying to achieve two different and incompatible goals."

Recently, at a system management sym posium in Huntsville, the same remark was repeated. "If it works, leave it alone."

The position established above indicates a marked lack of knowledge of the subject.

Engineering changes which are meaningful and complete can be prepared. However, all impact elements must be considered and their total cost and schedule impact included within the change package (Figure 2). This will result in a lower Engineering Change Proposal (ECP) or Value Engineering Change Proposal (VECP) rejection rate if the methodology and the formal procedural concepts of Configuration Management and Value Engineering are concurrently considered in both the establishment of the program and during its life cycle. Admittedly, if we are to propose changes to system equipment, they must be good, and if we expect them to be accepted by our customers, they must provide:

- Proof that the proposed change will correct a design deficiency

- Proof that the proposed change will accomplish the required performance and design requirements

- Proof that the proposed change will significantly improve performance and/ or reliability

- Proof of significant savings in dollars, personnel, and materials

During all phases of the program life cycle, extreme care must be exercised to include cost estimates of all the system elements affected by the value change. Corresponding effects on related systems must also be depicted as an estimated cost. Far too often, a value change is approved without considering its effect on the other systems. Figure 2 illustrates cost impact categories to be considered when estimating a value change:

The mere planning to incorporate a value change implies that the proposed change is expected to lower overall costs of the system. However, it has been repeatedly demonstrated that, in general, only a modest percentage of these proposals are ever incorporated due to the unavailability of a proper yard stick by which to measure full cost impact of the change. In most cases the immediate cost factor can be determined, but only when all ramifications of the cost are considered can the decision be made. In consequence, because of the lack of a rapid method for determining the extent of the cost factors, decision making is most difficult. Another major difficulty is the incompatibility of cost viewpoints on the part of the procuring agency and the contractor. Both are endeavoring an honest appraisal of the change, but one is considering cost impacts from procurement motives and the other from supply and profit motives. The solution, naturally, is a common meeting ground in which each facet of the change is determined and evaluated to the best advantage of both parties concerned. At the same time, the system itself must derive the greatest benefits relative to performance, reliability, safety, effectiveness, and other operational capabilities.

\section{Baseline Management and Cost Relationships}

Baselines (or points of departures) define the formal points by which changes in performance and design are controlled. These baselines are documented through approved specifications which are the basis for defining the system in terms of specified requirements. In turn, the specifications provide a defined base for determining contract costs and incentives.

Baselines are established at various planned intervals of the system or equipment life cycle, depending on the customer and the individual program requirements.

Baselines are also documented in terms of drawings, specifications, and other technical data required to fabricate, test, operate, maintain and logistically support the system. This type of baseline, usually called the "product configuration baseline" may be applied at any point during the acquisition phase of development.

Figure 3 illustrates the system life cycle and the required milestones which establish these baselines once completed and approved.

Baselines changes are accomplished in a prescribed manner in accordance with the configuration management manual requirements. All changes to these established baselines must be approved by the procuring activity.

By establishment of baselines, VECP's can be proposed during any phase of the system or program life cycle. A "before" or "was" condition now exists from which to impact new or revised requirements.

Figure 4 depicts VECP's or ECP's (Class I as defined by ANA Bulletin 445) required when these changes affect any of the elements which constitute the established baseline (or point of 
departure). Other baselines or points of depar tures may be established, depending upon the complexity of the program. Such baselines may be established by either the procuring agency or the contractor. For example, the following baselines may be established and may readily ensure system compatibility.

- Prototype design freeze baseline

- Tactical design baseline

- Engineering data baseline

- Technical data baseline

- Final product configuration baseline

Correspondingly, a complete system or contract end item need not have a baseline established at a specific point in time or within a single time frame. Incremental baselining of the system segments may suffice.

Those involved in Configuration Manage ment and Value Engineering must be knowledge able of the multitude of activities which occur in each phased segment of the system life cycle. Management procedures or definition networks, such as AFSCM 375-4, provides a road map to be followed in accomplishing mission objectives; orderly, economically, timely, and effectively. These procedures identify and define the establishment of baselines. Each activity or milestone to be accomplished during the life cycle of a typical major program is identified, defined, and primary responsibility assigned to appropriate organizational elements. The inter-relationships of these organizational elements, their responsibilities, and required inter-organizational coordination are clearly noted in appropriate detail within the scope of the procedure.

Figure 5 prescribes the multitude of milestones required to be accomplished during the contract definition phase as augmented by DOD Directive 3200.9 . "It is anticipated that the contract definition phase will result in (1) a substantial decrease in the number of changes made during the development cycle; (2) significant savings in total cost; (3) increase the deployed system's operational effectiveness, (4) the cancellation of fewer projects in full scale development; and (5) the reduction of side effects on other projects."

Figure 6 represents an interpretation of the prescribed multitude of milestones to be accomplished during the life cycle of a typical major program/project as augmented by NASA Policy Directive (NPD) number 7121-1, dated 28 October 1965. The directive prescribes NASA agencywide policy and guidelines for the planning, approva and conduct of major research and development projects.
The framework of these phases is as follows:

(1) Phase A effort involves the analysis of a proposed technical agency objective or mission in terms of alternate approaches or concepts, and the conduct of that research and technology development requisite to support that analysis and to as sist in determining whether the proposed technical objective or mission is valid.

(2) Phase B effort involves detailed study, analysis and preliminary design directed toward the selection of a single project approach from among the alternate approaches resulting from Phase $A$ activities.

(3) Phase C effort includes the detailed definition of the final project concept, including the system design and the breadboarding of critical systems and subsystems, as necessary to provide reasonable assurance that the technical milestone schedules and resource estimates for the next phase can be met, and that definitive contracts can be negotiated for Phase D.

(4) Phase D effort includes final hardware design and development, fabrication, test, and project operations.

Figure 7 depicts the commonality, differences and relationships of the Army, Air Force, and NASA phased segments for a typical major program's life cycle and its significant baselines established. It is intended to acquaint the reader and to give some order to the apparent confusion of how the DOD constitutents (Army and Air Force) and NASA do business.

The contractor who deals almost exclusively with one agency may never be appraised of the vast number of problems tha't evolve when dealing with two or more of the sequences. To effectively respond to the customers requirements the contractors must be keenly knowledgeable in this area,

VI. Configuration Management Requirement During the Life Cycle

Figure 8 represents the configuration management effort required during the system life cycle. Techniques of value engineering should be applied in determining the extent of application of each element to the program.

\section{Semantics and Education}

By far the most serious bottleneck to the implementation of Configuration Management and Value Engineering has been the problem of semantics and education. New terms are being generated; old terms are being modified. Following are terms and definitions currently in use. 
- System Engineering - The engineering management, direction, and control applied to a total system to ascertain and maintain overall technical integrity and integration of that specific system as related to design configuration, reliability and performance (AFSCM 375-1).

- Program Managernent - The process of planning, organizing, coordinating, controlling, and directing all effort to accomplish system/program objectives. (Manages all the effort that produces a system.)

- Configuration Management - Management of technical requirements which define systems (system equipment or individual equipment) and changes thereto. Implementation is provided through a formal set of procedural concepts by which uniform and mutually supporting methods for configuration identification, control, and accounting are established and maintained for nystems and system components. (AFSCM 375-1)

- Configuration - The complete technical description required to fabricate, test, accept, operate, maintain, and logistically support systems/equipment. (AFSCM 375-1)

- Configuration Accounting - Act of reporting and documenting changes made to a baseline configuration in order to establish a configuration status (system/equipment hardware or software). (AFSCM 375-1)

- Configuration Identification - The technical documentation (e.g., drawings and specifications, etc.) defining the approved configuration of systems/equipment under development, test, and production. (AFSCM 375-1)

- Configuration Control - Systematic evalua tion, coordination, and approval or dis approval of all baseline changes. (ASFCM 375-1)

- Value Engineering - Is the systematic application of techniques which:

a. Identify the function of a product or service.

b. Establish a value for that function.

c. Provide the function at the lowest overall cost.

- Baseline - An approved and defined point of departure for control of future changes in system or equipment performance and design. A baseline is documented by a specification and other documents and is technically defined by formal approval of the specification, or part thereof, by the procuring agency. (AFSCM 375-1)

- Product Configuration Baseline - A base line for a CEI technically defined by an approved Part II of a CEI specification and which is established by satisfactory completion of a first article configuration inspection (FACI). (AFSCM 375-1)

- Program Requirements Baseline - The baseline defined by the preliminary technical development plan (PTDP), program change proposal (PCP), military construction program (MCP, determination and findings (D\&F), and a general system performance/design requirements specification. (AFSCM 375-1)

- Design Requirements Baseline - A baseline which is technically defined by an approved Part I of the CEI specification. (AFSCM 375-1)

- Definition Baseline - A baseline established by release of system description. It is established prior to the initiation of the definition phase of development to which systems and equipment are controlled. (AMCR 11-26)

- Development Baseline - A baseline established by release of the development descriptions. It is established prior to the beginning of full scale development, to which design and hardware fabrication is controlled. (AMCR 11-26)

- Production Baseline - A baseline established by release of the technical data package. It is established prior to the commencement of production to which configuration end item manufacture and facility construction is controlled. This baseline is the basis for control during the production and operational periods.

- Mission Baseline - Defined and established by the approval of the feasibility study report package.

- Project Definition Baseline - Defined and established by the approval of the project definition plan.

- System Requirements Baseline - Defined and established by the approval of the system performance/design requirements specification and expanded project definition plan. 
- Design Requirements Baseline - Defined by the approved system package plan and Part I of the CEI specification. It is established by conducting a preliminary design review (PDR).

- Drawing Baseline - Defined by the approval of engineering data. It is established by conducting a critical design review.

- Product Baseline - Defined by the approval of Part II of the CEI specification and corresponding engineering and technical data manuals. It is established by conducting a first article configuration inspection (FACI).

\section{Why Configuration Management and Value Engineering?}

Principally, these management techniques exist because of the tremendous number of components and equipment incompatible with their parent systems. In compatibilities were not uncommon between systems procured by the same agency.

Our problem has been the lack of repeatibility. For example, chassis purchased for a single system under a single part number often differed drastically in internal configuration. In addition, we were developing and designing system equipment without definitized or specific functional requirements. The cost picture was nearly always neglected. A technique which would optimize system/equipment performance and concurrently produce system/equipment at minimum cost was needed.

It is readily apparent why Configuration Management and Value Engineering became required techniques. Following are examples of projects to which Configuration Management and Value Engineering techniques were not applied and the resultant costly recovery from this deficiency in our procurement systems:

- A customer refused to accept a system built for him because neither the cus tomer nor the contractor had maintained up-to-date descriptive documents accurately describing system configuration on the date of delivery.

o. A system was delayed for several months for conduct of a physical inventory of end item components (missiles) and associated repair parts (spares)/software.

- Two supposedly interchangeable models of ground station were found to require different antennae when mixed-pair duplex installation was attempted. Relocation and re-installation in samemodel pairs throughout the world was required.
- A missile was inadvertently launched due to stray EM radiation in co-location equipment (not a part of the missile's launch system).

IX. How Did These Deficiencies or Problems Occur?2

Because -

- Of our inability to determine exact end item hardware/software configuration from technical documentation.

- Configuration identification and accounting status records on the delivery date were inadequate to operate, maintain, and logistically support the operational system.

- Of our inability to determine status of changes incorporated at field locations, status of changes being processed, or status relative to approved changes.

- Repair parts/spares and technical orders/manuals were not updated to latest configuration, and were incompatible with the operational system.

- Of failure to meet program milestones for installation, checkout, and system integration. Technical description documentation was late, and inadequate for customer acceptance of the integrated system.

X. What Were the Fundamental Causes of all These Deficiencies? ${ }^{2}$

They were the result of:

- Inadequate system/equipment specifications.

- Contractual requirements for Configuration Management not definitive. Documentation required for configuration identification, control and status accounting not defined.

- Customer acceptance of end items deferred until turnover of total system.

- Late or lack of decision-making in management.

- Requirements for customer approval limited to major change of engineering significance only.

- Contractor lacks full appreciation of customer configuration management objectives, as well as understanding of the procedures. 
- Lack of centralized program management, resulting in the absence of total program integration.

- No management overview of the complete internal Configuration Management function and documentation flow between engineering groups and between engineering-manufacturing-material-test-product services or field operation organizations.

- Inadequate design review of changes from system and value viewpoint.

- Policies, procedures and documentation inadequate to integrate change control, identification and status accounting at both contractor and customer management levels.

- Inadequate documentation, status accounting, and maintenance of equipment $\log$ books.

Figure 9 portrays the type of teamwork that is required to successfully accomplish mission objectives at the lowest overall cost and at the earliest possible date. Are you a member of this management team?

\section{Implementing Documents}

The Department of Defense Constituents (Army, Air Force, and Navy) insist on the implementation of Configuration Management and Value Engineering.

The DOD Directive states: "It (Configuration Management) applies during the full scale development production and operational periods."

NASA insists on the implementation of Configuration Management and cost reduction. Although NASA has not insisted on the implementa tion of Value Engineering, the day is coming when it will be required.

Here are some of the implementing documents:

\section{A. Configuration Management}

- DOD Directive No. (Draft) dated January 1965

Air Force - AFSCM 375-1 dated 1 June 1964

Navy - ASW -5200.4 dated 13

December 1965

Army - Configuration Management Manual, AMCR 11-26 dated June 1955
- NASA - NPC 500-1 dated 18 May 1964

B. Value Engineering and Cost Reduction

- DOD Directive No. 5010.8 dated 6 August 1963

- DOD Handbook, H-111, Value Engineering

- MIL-V-38352 V.E. Program Requirements

Air Force - AFR 70-16, Value Engineering

Navy - NAVMAT 4858.2A dated 7 August 1964, Department of the Navy Value Engineering Program

Navy - SECNAVINST 4858. 2, Department of the Navy Value Engineering Program

Army - AR 11-26, Value Engineering

Army - AR 11-20, Army Cost

Reduction Program

Army - AR 700-20, Simplification of Material

Army - AR 705-5, Army Research \& Development

Army - AR 11-25, Reduction of Lead Time

ASPR Clause - 1-1704 through 1-1706 and Defense Procurement Circulars $\# 11,19,22$ and 26

- NASA - NASA Management Manual, Chapter 19-1-1, NASA's Policy on Cost Reduction

MSFC - Administrative Regulations and Procedure No. 19-2, Value Engineering

C. Phased Project Management

- DOD Directive No. 3200.9, Initiation of Engineering \& Operational Systems Development dated I July 1965

Air Force - AFSCM 375-4, dated 16 March 1964, Systems Program Manual

Navy - NAVSO P-2457, dated 1 July 1965, Department of the Navy RDT\&E Management Guide 
Navy - NAVMATINST 5200,11, dated

24 February 1965, Guide for the

Preparation of Project Master Plans

NASA - NASA Policy Directive No. 7121. 1

Army - AMCR 11-16, Planning and Control Guide

\section{Recommendations and Conclusions ${ }^{2}$}

Combat readiness is defined as organiza tional or equipment availability for combat operations (when applied to organizations and equipment). When applied to personnel, this means qualified to carry out combat operations in the unit to which they are as signed.

There should be a similar word for the space missions. Let's call it "Aerospace Readiness" meaning organizational and equipment availability for space missions.

Strategically speaking, the deficiencies described in the overall development cycle have been detrimental to our combat and aerospace readiness and in general to our defense posture and our prestige.

The counter insurgent action necessary to eliminate those problems is under way throughout the industry. Why use the term counter insurgent instead of counter? Because that is a more accurate description, "counter insurgent". From within each company, subcontractor and service there are men devoted and dedicated to this cause and determined to break the hard core that exists in management.

A recommendation to those in management is to establish a Configuration Management and Value Engineering program whose objectives are to ensure:

- Contract end items (CEI) are accurately defined, identified, controlled, and are compatible with related equipment/software.

- The status of CEI related software is known at all times and is compatible with the operational system.

- Data availability for reprocurement and maintenance.

- Adequate status accounting and maintenance of equipment $\log$ books by field organizations.

- Spares/repair parts are compatible with the latest configuration.
- The specific location and status of each CEI, by part and serial number, is known at all times during the design, development, and acquisition phase.

- The specific location and status of a CEI (that has been selected as a configured article) is known at all times by part and serial number.

- A configuration record (documenting all changes to the CEI and maintaining and distributing as required).

- Appropriate procedures, documentation, and organization are initiated and operating at the beginning of the definition phase to facilitate transition into formal Configuration Management.

- Documentation required by the customer for configuration identification, control, and status accounting are defined.

- Engineering release system is adequate to properly control the processing and formal release of engineering changes. All engineering files are maintained with updated data.

- Equipment changes and modifications required after the establishment of a baseline configuration will be controlled in accordance with appropriate customer requirements and specifically authorized for implementation by the customer's contracting officer.

- All proposed system/equipment changes are evaluated, resolved and approved or disapproved by the cognizant configuration control board (CCB) prior to implementation. (Evaluated both from a technical and value standpoint.)

- Program manager being responsible for making all decisions.

- Board members concurring or nonconcurring with Project Manager decision.

- The implementation of CCB decisions.

- The functional requirements established by the design requirements specifications are optimized to provide only what is essential to meet program objectives, thereby eliminating unnecessary functions.

- V.E. studies are selected (Preliminary Design Review) for review of CEI specifications and requirements. 
- "Cost visibility" to decision-making personnel during design and release.

- The formal procedural concepts developed by Configuration Management has the capability of identifying high cost areas and are systematically reviewed on a timely basis to eliminate unnecessary cost.

- The formal procedural concepts developed are optimized to provide the required function at the least overall cost without affecting its effectiveness.

Some within the aerospace industry and the military services have responded to the challenge; some have increased their capabilities in the realm of Configuration Management and Value Engineering. The simultaneous application of these techniques during all phases of weapon system development by both industry and the military managers, both technical and administrative, have produced system compatibility in the highly complex defensive systems guarding our nation at this time. The application of these techniques to aerospace development by NASA Managers has also produced system compatibility and tremendously aided our prestige image around the world.

However, it is the considered opinion of many, that in some instances the aerospace and weapon system industry and the services are still spinning their wheels. We just haven't responded enough to the challenge. Certainly there is room for improvement.

What is expected from all is a continuing coordinated effort aimed at resolving the complexities of present day procurement. With the obvious objective of achieving system compitibility and mission success, we must assure the nation of maximum value out of each and every procurement dollar.

The contractor who acts aggressively towards implementing a Configuration Manage ment and Value Engineering program will see an increase in profits through improved competitive stature. He must look to Value Engineering and Configuration Management as the means of achieving that end.

The Military and NASA customer, through the recognition of this need, must insure that such management be included in his procurement package.

Caution must be exercised however, since these techniques can be used to the disadvantage of both parties. Common industrial sense must be used in applying the proper exhibits or clauses.
Know your technique. Know and learn more about Configuration Management and Value Engineering. Both are compatible and will enhance any program.

The Department of Defense and NASA have during the last year developed and released new or revised manuals, directives, and specifications covering the requirements of Configuration Management and Value Engineering.

Configuration Management Manuals such as Air Force's AFSCM 375-1, NASA's NPC 500-1, Army's AMCR 11-26 and Navy's ASW -5200. 4 describe the minimum that is expected from both military and industry.

Value Engineering Documents such as Army's AR 11-20 (Army Cost Reduction Program), AR 11-26 Value Engineering Program, AMCR 11-23 U. S. Army Missile Command-VE-2, Value Engineering Program for Missile Systems, and Military Specification MIL-V-38352 V. E. Program Requirements describe the minimum that is expected from both military and industry.

The "How to do it" methodology has been left up to industry. It was not the Government's idea to dictate "How to do it". It was hoped that industry would respond loud and clear and with firm direction to implement these new techniques. This, however, has not been the case. Instead, industry has crept along waiting for the Government to fund the effort.

Released Configuration Management manuals and Value Engineering documents should be carefully studied. Answers to many questions heretofore unanswerable will be found. Configuration Management and Value Engineering is not a cure all, but only techniques which when used properly will enhance the probability that the systems will perform their required mission, within their performance, cost, and schedule milestones.

\section{References}

1 AIA (TCRC) Letter No. 65-41, dated June 24, 1961 from H. E. Shepley to AIA committees, paragraph 10 , page 8 , Part $I$.

2 AFSCP $375-2$, dated June 1, 1963, A Summary of Lessons Learned from Air Force Management Surveys. 


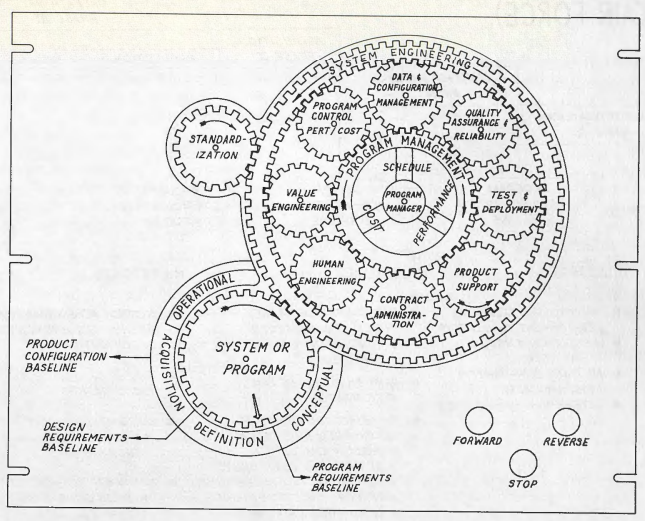

Figure 1 Management Relationships

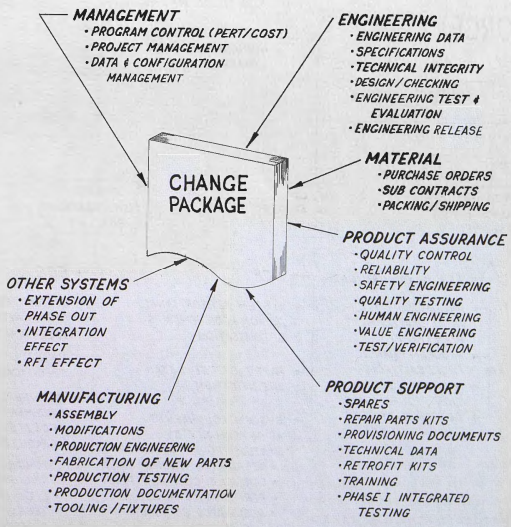

Figure 2 Cost Impact Categories and Sub-Element: 


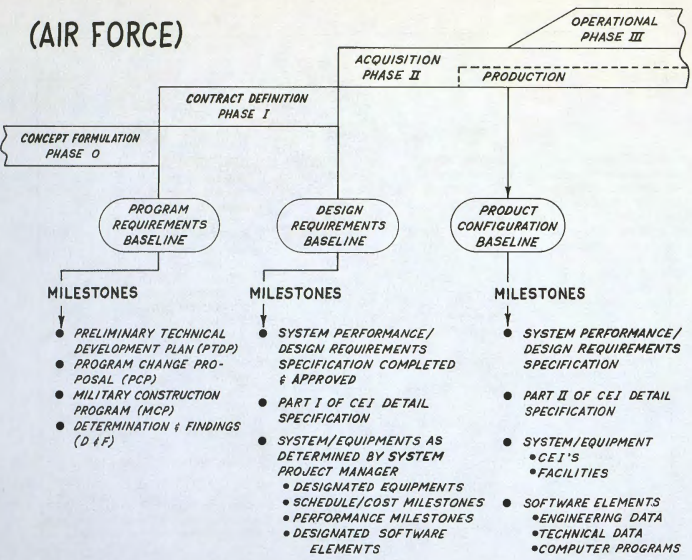

Figure 3 Baseline Management

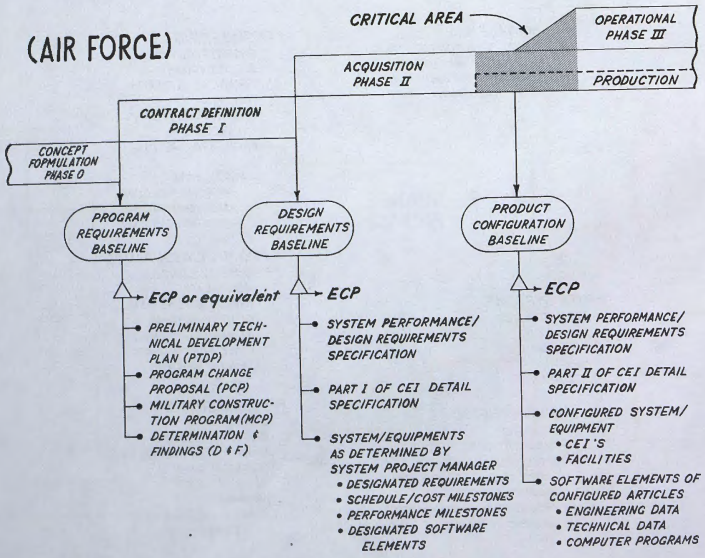

Figure 4 Changing A Baseline 


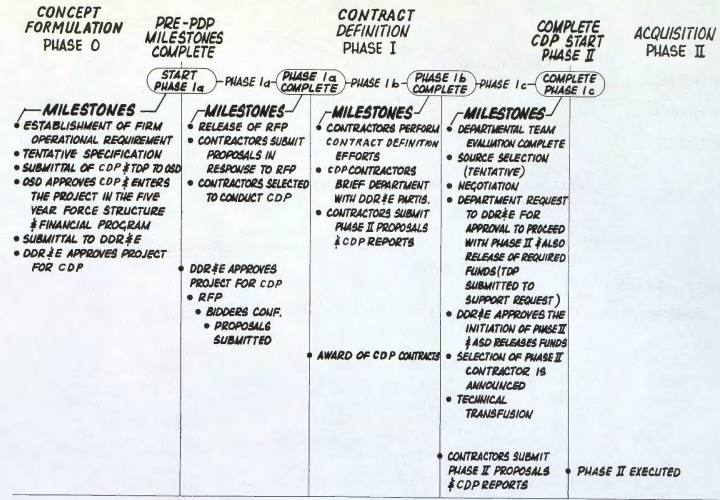

\section{TIME}

Figure 5 DOD's Contract Definition Phase

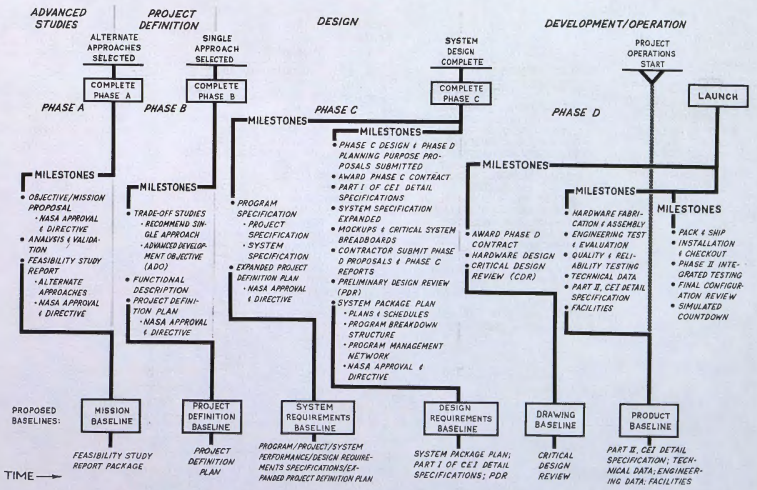

Figure 6 Interpretation of NASA's Phased Project Management 


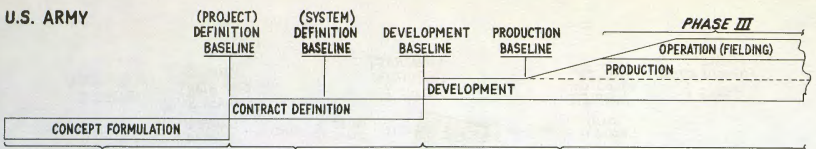

PHASE $O$ U.S. AIR FORCE

\begin{tabular}{|c} 
REQ \\
CONCEPT FORMULATION \\
PHASEO O
\end{tabular}

NASA
PHASE II

PRODUCT

CONFIGURATION

BASELINE

$\begin{array}{ccc}\text { SYSTEM } & \text { DESIGN } \\ \text { PROGRAM } & \text { REQUIREMENTS REQUIREMENTS }\end{array}$

BASELINE BASELINE BASELINE

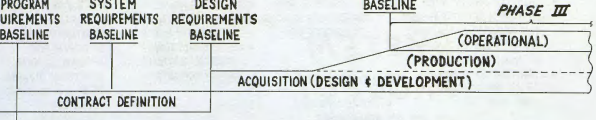

CONTRACT DEFINITIOI ACQUISITION (DESIGN \& DEVELOPMENT)

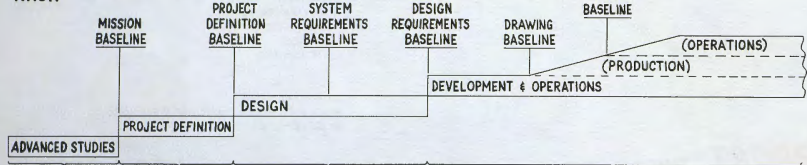

PHASE D

Figure 7 Phased Project Management Comparisons

PHASE III

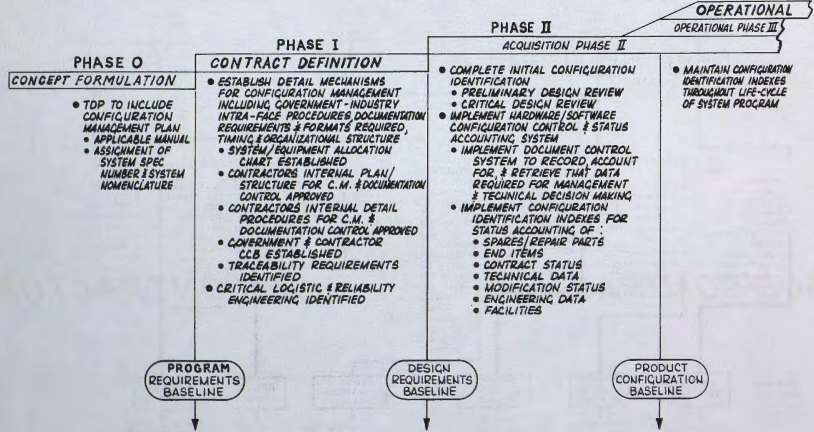

Figure 8 Configuration Management Requirements 


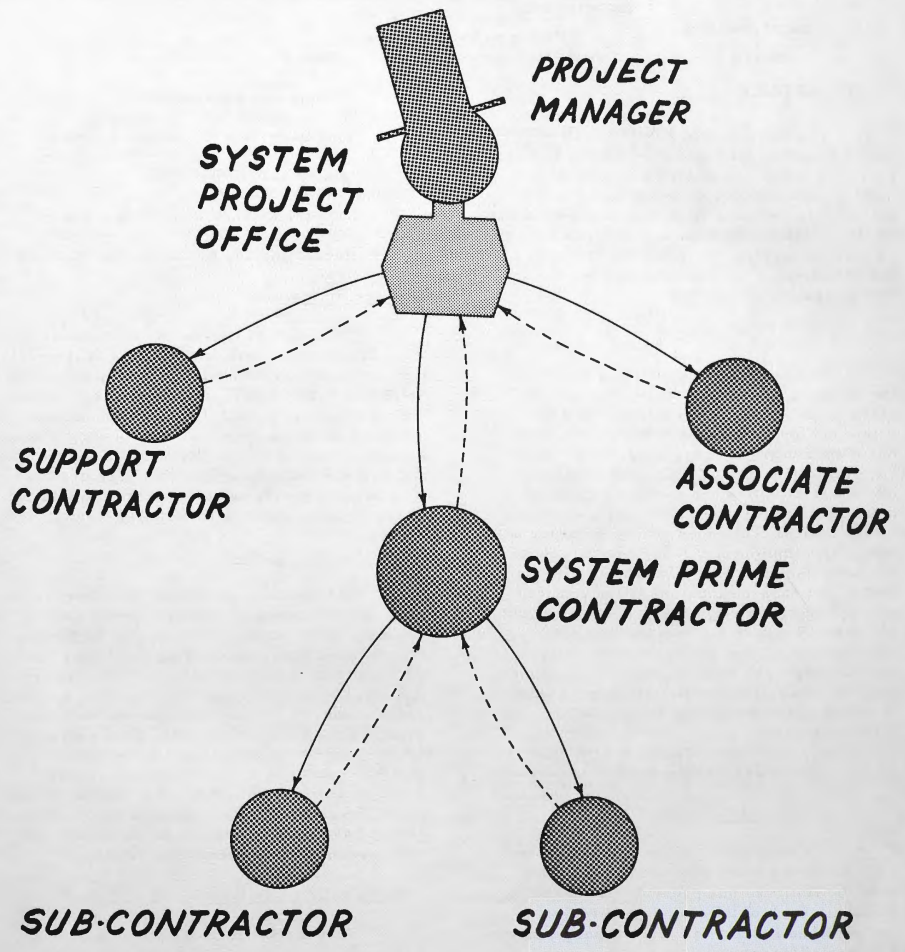

Figure 9 Intra-Organizational Team 